\title{
Evaluation of Salivary Alanine Aminotransferase Enzyme level in Smoker Patients with Peptic Ulcer in Relation to Periodontal Condition
}

\author{
Noor Sabah Irhayyim ${ }^{1}$, Maha Abdul Aziz Ahmed ${ }^{2}$ \\ ${ }^{1}$ Master student, Department of Periodontics, Collage of Dentistry, University of Baghdad \\ ${ }^{2}$ Prof, Master of periodontology, Department of periodontics, Collage of Dentistry, University of Baghdad
}

\begin{abstract}
Background: periodontal diseases are a group of chronic inflammatory disordered which divided into gingivitis and periodontitis while peptic ulcer involve ulceration of the epithelium lining of the stomach or duodenum or both of them. Smoking is a major health problem cause a harmful effect on both periodontium and gastrointestinal organs. Alanine aminotransferase (ALT) is commonly known as liver enzyme, its activity increase in many diseases such as peptic ulcer, hepatitis, chronic periodontitis and others. Aims of the study: Evaluate and compare the level of salivary ALT enzyme and the periodontal health status by measuring the clinical periodontal parameters (plaque index (PLI), gingival index (GI), bleeding on probing (BOP), probing pocket depth (PPD), clinical attachment level (CAL) and tooth loss $(T L)$ ), at the study groups ( group of smoker patients with peptic ulcer, group of non smoker patients with peptic ulcer, group of non smoker patients and without peptic ulcer (each group subdivided into gingivitis and chronic periodontitis), and control group), and correlate between the level of ALT salivary enzyme with clinical periodontal parameters. Materials and methods: Salivary ALT enzyme level and clinical periodontal parameters (PLI, GI, BOP, PPD, CAL, TL) were measured from 140 males, age range (25-40) years old, that divided into study groups which include,group of 40 smoker patients with peptic ulcer, group of 40 non smoker patients with peptic ulcer, and group of 40 non smoker patients and without peptic ulcer, then each of these groups subdivided into (20 had gingivitis and 20 had chronic periodontitis),also the control group which consists of 20 subjects without peptic ulcer and non smoker with clinically healthy periodontium. Results: The results showed that the highest median value of plaque index was in patients with gingivitis, peptic ulcer and smoker, while the median values of gingival index and bleeding on probing were highest among patients with gingivitis, peptic ulcer and non -smoker. The highest median values of probing pocket depth, clinical attachment level and tooth loss were recorded in patients with chronic periodontitis, peptic ulcer and smoker. The median value of salivary ALT enzyme (35.05) was found to be highest at patients had chronic periodontitis, peptic ulcer and smoker. All of the clinical periodontal parameters as well as salivary ALT enzyme level revealed highly significant differences in the comparisons among the study groups and subgroups. The correlations between the level of salivary ALT enzyme with clinical periodontal parameters were almost statistically non significant at the study subgroups and control group. Conclusions: It can be concluded that there was increase in periodontal tissue destruction and the level of salivary ALT enzyme associated with increase in the severity of periodontal diseases as well as the presence of peptic ulcer and smoking; accordingly, these results can suggest that salivary ALT enzyme is considered as a good biochemical marker of tissue destruction and measuring the level of this enzyme is consider as easy, time saving and non-invasive method of screening and early diagnosis of chronic periodontitis and to evaluate the effect of peptic ulcer and smoking on periodontal health status.
\end{abstract}

Keywords: Periodontal diseases, smoking, peptic ulcer, ALT salivary enzyme.

\section{Introduction}

Periodontal diseases are inflammatory conditions result from interaction between pathological bacteria and the host defense system that cause tissues damage. Bacterial plaque is the main cause of periodontal disease which is a microbial film that stick and embedded in a matrix of polymers of bacterial and salivary origin that form on teeth and on any hard and soft structures in oral cavity [1]. Gingivitis and periodontitis are the most common forms of periodontal diseases. Gingivitis, is a reversible inflammatory disorder that involve the soft tissue encompassed the teeth (the gingiva) without pocket formation or loss of attachment, while periodontitis in contrast to gingivitis that irreversible and involve the deeper structures of the periodontium and result in loss of attachment and destruction of alveolar bone[2] .Peptic ulcer is a common disorder of gastrointestinal system that involve the stomach (gastric ulcer)or duodenum(duodenal ulcer) that occur when there is ulceration in the epithelium lining the stomach or duodenum[3] .Mucosal injury happened whereas the balance between the peptic acid secretion and gastro mucosal defense is disrupted and that occur because of some aggressive factors which are non steroidal anti-inflammatory drugs (NSAIDs), Helicobacter pylori(H .Pylori)bacteria, alcohol, bile salt, gastric acid, smoking and pepsin[4,5) . Saliva is the liquid produced by the salivary glands , which considered a good biomarker because the collection of saliva is simple, non invasive, safe and does not need a special practitioner, as well as is useful to monitor various health and disease conditions in children, elderly, and when the collection of urine or blood is difficult[6].Alanine aminotransferase enzyme(ALT), this enzyme is usually found in plasma and in different body tissues but the most common site is the liver. The level of ALT is usually used as a biomarker for the health of the liver. The level of this enzyme is raised in many medical disorders such as hepatitis, diabetic, congestive heart failure and liver diseases[7]. The activity of this enzyme is increased in patients with chronic periodontitis [8] in addition in peptic ulcer patients[9].Smoking is one of the multifactorial that contribute in the pathogenesis of peptic ulcer and has a great effect on the epithelium lining of gastro intestinal system which decrease mucosal blood flow and delay healing of ulcer [10], while on the periodontium have a great effect by impair inflammatory and immune response to periodontal

\section{Volume 6 Issue 12, December 2017}




\section{International Journal of Science and Research (IJSR) \\ ISSN (Online): 2319-7064}

Index Copernicus Value (2016): 79.57 | Impact Factor (2015): 6.391

pathogen and the prevalence and severity of periodontal diseases are increased in smokers[11]. Hence, there was no pervious study concerning the correlation between periodontal health status, peptic ulcer, smoking and the level of ALTsalivary enzyme among men so, this study was designed and conducted.

\section{Materials and Methods}

The human samples included 140 males age from (25-40) years old. They were selected from the Department of Periodontology at the Teaching Hospital of College of Dentistry, University of Tikrit and from Baghdad/ Digestive System and Liver Teaching Hospital. Inclisioncriteria included 20 teeth present for each patient; patients with peptic ulcer(PU) diagnosed by gastrointestinal specialist via endoscope and smoker patients who smoke $>10$ ciglday for the last five years [12]. While the exclusion criteria were females, alcoholism, patients receive medication for treatment of peptic ulcer, have other systemic disease, undergone periodontal treatment or course of antiinflammatory, anti microbial or other medications in the 3 months before the study. Subject's acceptance documented by signing on specially designed informed consent. When the subjects had been selected, the whole un stimulated saliva collected after that the examination of clinical periodontal parameters (plaque index PLI [13], gingival index GI [14], bleeding on probing BOP[15], probing pocket depth PPD [15], clinical attachment level CAL[16], and tooth loss TL[17] were carried by using the Michigan O periodontal probe on four surfaces (mesial, distal, lingual/palatal, buccal/labial ) of all teeth except third molars that were excluded. Subjects shared in the study divided into four study groups:

1) Group (no.=40) : consisted of patients with peptic ulcer and smoker.

2) $\operatorname{Group}($ no. $=40)$ : consisted of patients with peptic ulcer and non smoker.

3) $\operatorname{Group}($ no. $=40)$ : consisted of patients without peptic ulcer and non smoker.

Each group subdivided according to periodontal health status into:

Gingivitis (Ging.)subgroup(no.=20).

Chronic periodontitis (CP) subgroup(no.=20).

Gingivitis: was defined by the presence of signs and symptoms of gingival inflammation[14], and without periodontal pocket or clinical attachment loss.

Chronic periodontitis: was defined by the presence of at least four sites with $\mathrm{PPD} \geq 4 \mathrm{~mm}$ and clinical attachment loss of (1-2mm) or more, this made according to the system of international classification for periodontal disease (PD) [18].
4-Control group(no.=20): consisted of subjects without peptic ulcer and non smoker with clinically healthy periodontium.

Healthy periodontium: was defined by the absence of any signs and symptoms of gingival inflammation and without periodontal pocket or clinical attachment loss.

The whole unstimulated saliva samples about $3 \mathrm{ml}$ were collected[19]. Samples centrifuged at $1000 \mathrm{rpm}$ for 10 minutes then the supernatant saliva stored at $-20^{\circ} \mathrm{C}$ (freezer) until biochemical analysis of ALT enzyme. The statistical analysis included were descriptive (median and percentages (\%)) and inferential (Kruskal-Wallis H test, Mann-Whitney U test, and Simple person's correlation coefficients (r). In the statistical tests, the levels of significant(S) when $0.05 \geq P \geq 0.01$, non significant (NS) when $\mathrm{P}>0.05$, while highly significant (HS) when $\mathrm{P} \leq 0.01$. We certify that this study involving human subjects is in accordance with the Helsinki declaration of 1975 as revised in 2013 and that it has been approved by the relevant institutional Ethical Committee[20].

\section{Results}

Table (1), showed that the highest median value of PLI (3.53) was at Ging.+PU+Smoker, while the highest median values of GI and BOP $(3.39,30.7)$ respectively were at Ging.+PU+Non-smoker. The highest median values of PPD, CAL, and TL $(6.62,6.87,18.19)$ respectively were at $\mathrm{CP}+\mathrm{PU}+$ Smoker ; hence, highly significant differences were revealed among the study subgroups for all clinical periodontal parameters. Table (2) presented that the highest median value of salivary ALT enzyme (35.05) at $\mathrm{CP}+\mathrm{PU}+$ Smoker, while the lowest median value (9.95) at Control group, and demonstrated highly significant difference among the study subgroups and control group. Table (3) showed almosthighly significant differences between pairs of the study subgroups and control group while, significant differences between Ging.+PU+Nonsmoker with both Ging.+PU+Smoker and control group as well as, between Ging.+PU+Smoker with $\mathrm{CP}+\mathrm{PU}+$ Nonsmoker. Table (4) demonstrated the correlations between salivary ALT enzyme with each one of the clinical periodontal parameters were almost non-significant weak correlations however, a non-significant moderate negative correlation with PLI at CP+PU+Non-smoker while, Tooth loss demonstrated non-significant moderate correlation with ALT enzyme which was negative at $\mathrm{CP}+\mathrm{PU}+\mathrm{Non}-\mathrm{smoker}$ but it was positive at Ging.+PU+Non-smoker.

Table 1: Statistical analysis of the clinical periodontal parameters of the study subgroups and control group

\begin{tabular}{|c|c|c|c|c|c|c|}
\hline \multirow{2}{*}{ Groups and subgroups } & PLI & GI & BOP score 1 & PPD & CAL & $T L$ \\
\cline { 2 - 7 } & Median value & Median value & Median \% & Median value & Median value & Median \% \\
\hline CP+PU+Smoker & 2.05 & 1.52 & 17.95 & 6.62 & 6.87 & 18.19 \\
\hline Ging.+PU+Smoker & 3.53 & 2.56 & 23.25 & - & - & 1.603 \\
\hline CP+PU+Non-smoker & 1.58 & 1.91 & 25.84 & 5.32 & 5.42 & 11.75 \\
\hline Ging.+PU+Non-smoker & 3.06 & 3.39 & 30.7 & - & - & 1.06 \\
\hline CP & 1.06 & 1.09 & 18.55 & 4.12 & 4.47 & 3.73 \\
\hline Ging. & 2.55 & 2.02 & 28.95 & - & - & 0.35 \\
\hline Control group & 0.39 & 0.35 & - & - & - & 0 \\
\hline
\end{tabular}

Volume 6 Issue 12, December 2017 


\section{International Journal of Science and Research (IJSR) ISSN (Online): 2319-7064}

Index Copernicus Value (2016): 79.57 | Impact Factor (2015): 6.391

\begin{tabular}{|c|c|c|c|c|c|c|}
\hline $\begin{array}{c}\text { Kruskal -wallis H test without } \\
\text { control group }\end{array}$ & 115.77 & 112.86 & 106.64 & 40.06 & 39.84 & 31.75 \\
\hline P-value & 0.000 & 0.000 & 0.000 & 0.000 & 0.000 & 0.000 \\
\hline Sig. & HS & HS & HS & HS & HS & HS \\
\hline
\end{tabular}

Table 2: Statistical analysis of the salivary ALT enzyme concentration (IU/L) of the study subgroups and control group

\begin{tabular}{|c|c|c|c|c|}
\hline Groups and subgroups & Median & Kruskal-Wallis H test & $P$-value & Sig. \\
\hline $\mathrm{CP}+\mathrm{PU}+$ Smoker & 35.05 & \multirow{7}{*}{131.304} & \multirow{7}{*}{0.000} & \multirow{7}{*}{ HS } \\
\hline Ging.+PU+Smoker & 21.25 & & & \\
\hline $\mathrm{CP}+\mathrm{PU}+$ non-smoker & 32.55 & & & \\
\hline Ging.+PU+non-smoker & 18.8 & & & \\
\hline $\mathrm{CP}$ & 21.05 & & & \\
\hline Ging. & 14.6 & & & \\
\hline Control group & 9.95 & & & \\
\hline
\end{tabular}

Table 3: Comparisons of the median values of ALT salivary concentration enzyme between all pairs of the study subgroups and control group

\begin{tabular}{|c|c|c|c|c|}
\hline \multicolumn{2}{|c|}{ Groups and sugroups } & Mann-Whitney U test & $P$-value & Sig. \\
\hline \multirow{6}{*}{ Ging.+PU+Smoker } & $\mathrm{CP}+\mathrm{PU}+$ Smoker & 50.12 & 0.002 & $\mathrm{HS}$ \\
\hline & Ging.+PU+Non-smoker & 25.15 & 0.049 & $\mathrm{~S}$ \\
\hline & $\mathrm{CP}+\mathrm{PU}+$ Non-smoker & 31.62 & 0.013 & $S$ \\
\hline & Ging. & 49.12 & 0.003 & $\mathrm{HS}$ \\
\hline & $\mathrm{CP}$ & 20.22 & 0.662 & $\mathrm{NS}$ \\
\hline & Control group & 69.12 & 0.000 & $\mathrm{HS}$ \\
\hline \multirow{5}{*}{$\mathrm{CP}+\mathrm{PU}+$ Smoker } & Ging.+PU+Non-smoker & 75.27 & 0.000 & $\mathrm{HS}$ \\
\hline & $\mathrm{CP}+\mathrm{PU}+$ Non-smoker & 18.5 & 0.148 & $\mathrm{NS}$ \\
\hline & Ging. & 79.25 & 0.000 & HS \\
\hline & $\mathrm{CP}$ & 52.35 & 0.001 & HS \\
\hline & Control group & 90.25 & 0.000 & HS \\
\hline \multirow{4}{*}{ Ging.+PU+Non-smoker } & CP+PU+Non-smoker & 56.77 & 0.000 & $\mathrm{HS}$ \\
\hline & Ging. & 23.97 & 0.061 & $\mathrm{NS}$ \\
\hline & $\mathrm{CP}$ & 22.92 & 0.073 & $\mathrm{NS}$ \\
\hline & Control group & 43.97 & 0.012 & $\mathrm{~S}$ \\
\hline \multirow{3}{*}{$\mathrm{CP}+\mathrm{PU}+$ Non-smoker } & Ging. & 80.75 & 0.000 & $\mathrm{HS}$ \\
\hline & $\mathrm{CP}$ & 33.65 & 0.08 & $\mathrm{NS}$ \\
\hline & Control group & 88.75 & 0.000 & $\mathrm{HS}$ \\
\hline \multirow{2}{*}{ Ging. } & $\mathrm{CP}$ & 46.9 & 0.005 & $\mathrm{HS}$ \\
\hline & Control group & 20 & 0.118 & $\mathrm{NS}$ \\
\hline Control group & $\mathrm{CP}$ & 66.9 & 0.000 & $\mathrm{HS}$ \\
\hline
\end{tabular}

Table 4: Correlation between the level of salivary ALT enzyme with the clinical periodontal parameters at each study subgroup and control group

\begin{tabular}{|c|c|c|c|c|c|c|c|}
\hline Groups and subgroups & Statistical Analysis & $P L I$ & $G I$ & BOP Score1 & $P P D$ & $C A L$ & Tooth Loss \\
\hline \multirow{3}{*}{$\mathrm{CP}+\mathrm{PU}+$ Smoker } & $\mathrm{r}$ & 0.018 & -0.122 & -0.277 & -0.057 & 0.158 & -0.267 \\
\hline & $\mathrm{P}$ & 0.940 & 0.608 & 0.238 & 0.811 & 0.507 & 0.337 \\
\hline & Sig. & NS & NS & NS & NS & NS & NS \\
\hline \multirow{3}{*}{ Ging.+PU+Smoker } & $\mathrm{r}$ & -0.181 & -0.303 & 0.162 & . & . & 0.105 \\
\hline & $\mathrm{P}$ & 0.444 & 0.194 & 0.495 & . & . & 0.895 \\
\hline & Sig. & NS & NS & $\mathrm{NS}$ & . & . & NS \\
\hline \multirow{3}{*}{$\mathrm{CP}+\mathrm{PU}+$ Non-smoker } & $\mathrm{r}$ & -0.463 & -0.316 & -0.248 & 0.224 & -0.063 & -0.426 \\
\hline & $\mathrm{p}$ & 0.070 & 0.175 & 0.293 & 0.343 & 0.793 & 0.113 \\
\hline & Sig. & NS & NS & NS & NS & NS & NS \\
\hline \multirow{3}{*}{ Ging.+PU+Non-smoker } & $\mathrm{r}$ & 0.081 & 0.039 & 0.019 & . & 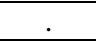 & 0.577 \\
\hline & $\mathrm{P}$ & 0.733 & 0.873 & 0.936 & . & . & 0.423 \\
\hline & Sig. & NS & NS & NS & . & . & NS \\
\hline \multirow{3}{*}{$\mathrm{CP}$} & $\mathrm{r}$ & 0.194 & -0.291 & -0.302 & 0.197 & 0.161 & 0.072 \\
\hline & $\mathrm{P}$ & 0.412 & 0.213 & 0.159 & 0.406 & 0.499 & 0.854 \\
\hline & Sig. & NS & NS & NS & NS & NS & NS \\
\hline \multirow{3}{*}{ Ging. } & $\mathrm{r}$ & -.008 & -0.098 & 0.036 & . & . & . \\
\hline & $\mathrm{P}$ & 0.974 & 0.680 & 0.879 & . & 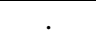 & . \\
\hline & Sig. & NS & $\mathrm{NS}$ & $\mathrm{NS}$ & & & \\
\hline \multirow{3}{*}{ Control group } & $\mathrm{r}$ & 0.132 & -0.063 & & & & \\
\hline & $\mathrm{P}$ & 0.578 & 0.421 & & & & \\
\hline & Sig. & NS & NS & & & & \\
\hline
\end{tabular}

Volume 6 Issue 12, December 2017 www.ijsr.net

Licensed Under Creative Commons Attribution CC BY 


\section{International Journal of Science and Research (IJSR) \\ ISSN (Online): 2319-7064}

Index Copernicus Value (2016): 79.57 | Impact Factor (2015): 6.391

\section{Discussion}

The results showed that the median value of PLI was highest at Ging.+PU+Smoker subgroup with a highly significant difference among the study subgroups. This may be due to the major role of dental plaque in the pathogenesis and development of periodontal disease(PD). The oral biofilm consists of different microganisms (m.o.), one of these m.o. is $H$. pylori bacteria that consider the main cause of peptic ulcerdevelopment [21], Desai et al. in 1991 [22] , found that there was at least one strain of $H$. pylori bacteria isolated from the plaque was genetically closely related to identical strain from the stomach, suggesting that this bacteria in the dental plaque had a potential for gastric infection. Smoking is a major health problem for the development and progression of PD and peptic ulcer which interfere with vascular and immunological functions and delay of healing of both diseases [23,24]. Karem et al. in 2013 [25], revealed that higher mean values of PLI was found in smokers when compared with non smokers for systemically healthy individuals. This study showed highly significant differences among the study subgroups, although the increased gingival inflammation represented by highest median values of GI and BOP sites score (1) were found among Ging.+PU+Non-smoker subgroup. The absence of good oral hygiene lead to accumulation of dental plaque and gingival inflammation with development of gingivitis[26]. Nicotine in cigarette smoking cause vasoconstriction in gingival blood vessels with decrease bleeding on probing [27]. Abdul Ameer ALubaba and Ali GhBasima in 2015 [28], found that there were highly significant differences in GI and BOP in smokers when compared with non smokers. The median values of PPD and CAL were found to be highest at $\mathrm{CP}+\mathrm{PU}+$ Smoker subgroup than other subgroups with statistically highly significant difference. Patients with peptic ulcer had increased PPD and CAL associated with gingival recession, also patients with PPD $\geq 5 \mathrm{~mm}$ had higher quantity of $H$. Pylori in the subgingivalplaque[26]. Ali GhBasima and Ali $\mathrm{H}$ Omar in 2012[29]; Ali H Omer in 2015 [23], revealed that there were significant differences with higher mean values of the clinical periodontal parameters( PPD, and CAL) in smokers group compared to non smokers both with $\mathrm{CP}$. The highest median percentage value for TL detected in $\mathrm{CP}+\mathrm{PU}+$ smoker subgroup. The CP is an inflammatory disorder caused by a pathogenic microbiota in the subgingival biofilm that trigger innate, inflammatory, and adaptive immune responses. These processes result in the destruction of the tissues surrounding and supporting the teeth, and eventually in tissue, bone and finally TL, so that TL is the end stage of periodontitis after periodontal pocket formation and loss of clinical attachment [30] .Molly et al., in 2004 [31] revealed that patients with peptic ulcer had loss of bone with missing number of teeth.Smoking increased the severity of PD by increase bone loss, clinical attachment loss and gingival recession, so that smoker subjects had number of missing teeth [32] .The ALT enzyme is an intracellular enzyme including in metabolic process and mostly present in the cells of the tissue. It is commonly known as liver enzyme. The higher level of this enzyme is an indicator of cellular damage and increase its activity in gingival crevicular fluid(GCF) and saliva is consequence of release from the damaged cells of soft tissue of periodontium and reflection of metabolic change in the inflamed gingiva [33] .In this study, the highest median value of ALT salivary enzyme showed in $\mathrm{CP}+\mathrm{PU}+$ Smoker. It was detected that the level of ALT salivary enzyme was statistically significantly increased in patients with $\mathrm{CP}$ as compared with control group and there were linear increase in its level with increase in the severity of PD[33]. The ALT salivary enzymeis among the most important salivary biochemical marker which is released in response to a variety of diseases such as peptic ulcer that ocurr when open craters or sores develop in the inner lining of the stomach (gastric ulcer) or the duodenum (duodenal ulcer) as a result of disruption of protective mechanisms, and the activity of this enzyme increased in this medical problem that liberate from the damaged mucose of the gastrointestinal organ and elevated in the extracellular fluid. It was found that the level of ALT salivary enzyme was significantly increased in peptic ulcer patients when compared with non peptic ulcer subjects[9] .Smoking is considered an aggressive factor for peptic ulcer and PD. Concerning the peptic ulcer, smoking impair the therapeutic effect of histamine 2-antagonist, stimulate the pepsin secretion, promote reflux of duodenal content into the stomach, increase the risk of harmful effect of $H$. pylori and increase the production of free radicals and platelet activating factor; in addition, has a great effect in the development and delay healing of peptic ulcer by decrease gastric mucosal blood flow[10]. While for PD, smoking impair inflammatory and immune response to periodontal pathogen, cause defect in neutrophil function and vasoconstriction in the area [11].Heavy smokers usually revealed significant increase in the level of ALT enzyme in serum and saliva when compared to non smoker subjects because smoking cause a damage to the liver cells which lead to increase in the level of this enzyme and lead to liberation of it into the extracellular fluid [34]. The findings of this study revealed that there were almost non-significant correlations between ALT enzyme and clinical periodontal parameters except between ALT enzyme and PLI in $\mathrm{CP}+\mathrm{PU}+$ Non-smoker which was a non-significant moderate negative correlation and non-significant moderate correlations for TL at Ging.+PU+Non-smoker as well as CP+PU+Non-smoker. Hence, Totanet al.,2006[35] ; AbdulHadi J Mustafa and Alsafi A Khulood, 2009[36] found that salivary ALT activity was statistically non significantly modified in patients with PD (chronic periodontitis had PPD $>5 \mathrm{~mm}$, bleeding on probing, and alveolar bone loss $>40 \%$ ) as compared with the control group. However, Todorovicet al.,2006[37] detected that there was a strong positive correlation between the activity of salivary ALT enzyme and the mean value of the GI in patients with $\mathrm{CP}$. The weak non-significant correlations detected in this study, may be due to the presence of more inactive sites during the saliva collection or due to small human sample size in each subgroup.In conclusion, salivary ALT enzyme can be used as a biochemical marker for the PD, peptic ulcer and smoking so it may contribute in diagnosis, assessment of risk, progression and prognosis of severity of tissue destruction caused by these diseases.

\section{Volume 6 Issue 12, December 2017}




\section{International Journal of Science and Research (IJSR) \\ ISSN (Online): 2319-7064}

Index Copernicus Value (2016): 79.57 | Impact Factor (2015): 6.391

\section{References}

[1] American Academy of periodontology( AAP). 2004. The pathogenesis of periodontal disease. J periodontal, 70:457-470. IVSL.org.

[2] Carranza, Newman Taki, and Klokevold. 2015. Carranza's clinical periodontology. Elsvier Saunders, 12th edition.

[3] Palmer , Penman. 2006. Davidson's : principle and practice of medicine : A textbook of general medicine.

[4] Michael A Siegel. 2008. Burkets: A text book of oral medicine.

[5] Chan FK and Graham DY.2004.Prevention of nonsteroidal anti-inflammatory drug gastrointestinal complications - review and recommendations based on risk assessment. Review article:Prevention of nonsteroidal anti-inflammatory drug gastrointestinal .April, vol.19, P . 1051-1061.

[6] Chiappin S, Antonelli, Gatti R, Depalo EF. 2007. Saliva specimen : A new laboratory Tool for Diagnosis and Basic investigation. J clinchimActe; 383 (1) : 3040.

[7] Paul T and Giboney MD 2005. Mildly elevated liver transaminase level in the a symptomatic patients. American Family Physician, vol.71, no. 6, march 15.

[8] SairtaDabra, Kamapreet China and AlkaKauskik. 2012. Salivary enzymes as a diagnostic markers for detection of gingival / periodontal disease and their correlation with the severity of the disease. J Indian Soc. Periodontal , July-september; 16(3):358-364.

[9] Moslem Boghori ,MahmoudrezaAghamaal, ReyhanehSariri, FahimeMohamad Pour, HoseinGhafour. 2014. Salivary enzyme and flow rate: Markers of peptic ulcer. Journal of oral biology and craniofacial research (4): 24-29.

[10] Maity P, Biswask, Roys , Banerjee RK, Bandyopadhgay U.2003. Smoking and the pathogenesis of gastrointestinal ulcer- recent mechanistic update. Mol cell Biochem. ,253(1-2): 32938.

[11] Underner M, Maes I, Urban T, Mentice JC. 2009. Effect of smoking on the periodontal disease. US National Library of Medicine, National institute of health, December; 26(1): 1-8.

[12] Maffei G Brouwer N. ,Dolman KM, Van der velden U. ,Roos D, Loose BG. 2005. Plasma levels of mannanbinding lectin in relation to periodontitids and smoking J periodontal , 76: 1881-9.

[13] Sliness J and Löe H. 1964. Periodontal disease in pregnancy II. Acta. OdontoScand, 24:747-749

[14] Löe H .1967. Gingival Index , the plaque Index and the retention index system. J Clin periodontal 38:610-616.

[15] Carranza, Newman Taki, and Klokevold. 2012. Carranza's clinical periodontology. Elsevier Saunders, 11th edition (chapter 4, P 41-42)and (chapter 27, P 305-308).

[16] American Academy of periodontology (AAP).1999. Parameters on chronic periodontitis with slight to moderate loss of periodontal support (supplement). J periodontal, may.vol. 71 , no. 5, P.853-855.

[17] Chei-Kaneto, Satoshi Toyokawa, KazioInone, Marko Inone, Toshihiko Senba, YasuoSuyama, Yuji Myoshi, Yauski Kobayashi. 2012. Association between periodontal disease and peptic ulcers among Japanese workers: My health up study . Global Journal of health science, vol. 4, no. 2, march

[18] Lang NP, Bartold PM, Cullinam M,et al.1999. International classification workshop. Consensus report : chronic periodontitis . Annals of periodontology , 4:53.

[19] Bradely Stephen Henson and David T.Wong.2010.Collection, storage, and processing of saliva samples for downstream molecular application. Spring science business media, 26 July, vol.666,P. 2133.

[20] World Medical Association 2013. Declaration of Helsinki Ethical Principles for Medical Research Involving Human Subjects. JAMA.310(20):21912194.

[21] Isabel Adler,Andrea Muino, Silva Aghas, Laura Harada, Mariana Diaz, Adriana Lence, Mario Labborozzi, Juan Manual , Boris Elsner, Alejandra Avagnine, Valeria Denninghoff. 2014.Helicobacter Pylori and oral pathology relationship with the gastric infection . World Journal of Gastrenerology , Aug. 7, 20(29): 9922-9935.

[22] Desai HG, Gill HH, ShankranK, Mehta PR, Prabhu SR.1991. Dental plaque : a permanent reservoir of Helicobacter pylori. Scand J Gastroenterol, 12051208.Nov.26(11) p.1205-1208.

[23] Ali H. Omer. 2015. The effect of cigarette smoking on salivary IgA and periodontal disease . Journal of Baghdad collage of dentistry, vol. 27, issue 3, p. 116 119.

[24] Li Luf, Chan RL, LuL, Shen J, Zhang L, WnWk, Wang L, Hut, Li Mx, Cho CH.2014. Cigarette smoking and gastrointestinal disease: The causal relationship and underlying molecular mechanisms. Int. J Mol Med, Aug.; 34(2): 72-80.

[25] karem, Ban Ibrahim, lekaa M 2013. Periodontal health status and salivary enzymes levels in smokers and non smokers: comparative cross sectional study.vol.25(3),September., p. 91-96.

[26] Sophia Marbiax ,AssemSoudied , Maya Romani, GnillaumaCompard , Gills Amador, zahahiPadrann. 2013. Helicobacter Pylori and periodontal disease: An update and proposal of a multidisciplinary clinical protocol. Open Journal of stomatology, 13 June, 3:318322.

[27] Kumar Vijaya ,Faizuddin Mohamed. 2011. Effect of smoking on gingival micrivasculature: A histological study. J Indian Periodontal, Dec.15(4):344-348.

[28] Abdul Ameer A Lubaba and Ali Gh Basima.2015. Effect of light smoking on the salivary levels of alkaline phosphatase and osteocalcin in chronic periodontitis patients. $\mathbf{J}$ of Baghdad collage of Dentistry, vol.27, issue2, page:110-114.

[29] Ali G. Basimaand Ali H Omer. 2012. Detection of salivary flow rate and minerals in smokers and non smokers with chronic periodontitis (clinical and biochemical study). Journal of Baghdad collage of Dentistry, vol. 24, issue 1 P.:68-7.

[30] Nora Silva,Loreto Abusleme, Denisse Bravo, Nicolas Dutzan, Jocelyn Garcia-Sesnich, Rolando Vernal, Marcelo Hernandez and Jorge Gamonal. 2015. Host 


\section{International Journal of Science and Research (IJSR) \\ ISSN (Online): 2319-7064}

Index Copernicus Value (2016): 79.57 | Impact Factor (2015): 6.391

response mechanism in periodontal diseases. J Appl. Oral. Sci., May-Jun.;23(3):329-355.

[31] Molly J,Wolff LF, Lopez-Gizman, et al.2004. The association of periodontal disease parameters with systemic medical condition and tobacco use. $\mathbf{J}$ clinperiodontal, 31:25-32.

[32] Albandar JM, Streckus CF, Adesanya MR, Winn DM. 2000. Cigar, pipe, cigarette smoking as risk factors for periodontal diseases and tooth loss. J periodontal, Dec.;71(12):187-81.

[33] Luka R, Khan SN, Iqbal PS, Soman RR, Chalkarayan J, Krishman V.2015. Estimation of specific salivary enzymatic biomarkers in individuals with gingivitis and chronic periodontitis : A clinical and biochemical study. J Int. oral health, September 7(9): 54-7.

[34] Wannamethee SG and Shaper AG. 2010. Cigarette smoking and serum liver enzymes: the role of alcohol and inflammation. Ann ClinBichem., Jul. 47(4):321-6.

[35] Totan A, Greabu M, Totan C, Spinu T.2006. salivary aspartate aminotransferase, alanine aminotransferase, and alkaline phosphtase possible marker in periodontal diseases. Clinchem Lab med; 44(5); 612-5.

[36] Abdul- Hadi J Mustafa and Alsafi A Khulood. 2010. Evaluation of salivary enzymes activities among patients with chronic periodontitis. $\mathbf{J}$ of Baghdad university collage of Dentistry. Vol.22(1):1-3.

[37] Todorovic T,Pozic I, VicentaBarriero M, Ljukovic B., Pejovic J, Kenezevc M. 2006.Salivary enzymes and periodontal disease . Med. Oral pathology oral cirBucal, 11:115-9. 